\title{
Development and Validation of Physical Science Workbook for Senior High School
}

\author{
Danilo V. Rogayan Jr. ${ }^{1 *}$, Lea F. Dollete ${ }^{2}$ \\ ${ }^{1}$ College of Education, Arts \& Sciences, President Ramon Magsaysay State University - San Marcelino, Zambales, Philippines, ${ }^{2} \mathrm{College}$ of Teacher \\ Education, President Ramon Magsaysay State University - Botolan, Zambales, Philippines
}

*Corresponding Author: danrogayan@prmsu.edu.ph

\section{ABSTRACT}

With the recent implementation of the K-12 curriculum in the Philippines, teachers are challenged to develop relevant, research-based, and responsive instructional materials. At present, few reference materials for use have been prepared for the required senior high school (SHS) competencies. This study developed a workbook in physical science for SHS based on the students' least learned concepts in a government-owned university in Central Luzon, the Philippines. Results revealed that the developed workbook was found to be very much acceptable $(M=3.90)$ by expert validators. In particular, the workbook was acceptable in terms of adequacy $(M=3.85)$, coherence $(M=3.90)$, appropriateness $(M=3.90)$, and usefulness $(M=3.95)$. Student-validators who were enrolled in a physical science course also rated the workbook acceptable $(\mathrm{M}=3.79)$. The validated material is recommended for use as supplemental instructional tool in physical science course in the SHS. The material which was anchored to the analysis, design, development, implementation, and evaluation model may serve as a prototype for the development of workbooks for other courses in the K-12 SHS curriculum. Further review and evaluation of the workbook may be considered to make it more contextualized, localized, and indigenized in the Philippine setting.

KEY WORDS: instructional material; material development; physical science workbook; science education; senior high school

\section{INTRODUCTION}

T he fast-paced changing world and the challenges of the Fourth Industrial Era continue to transform the educational landscape of today. Educators are challenged by the demanding task of educating Generation $\mathrm{Z}$ to keep them abreast with the digital world. Globally, the Philippines lags behind other countries in terms of the quality of education, particularly in science education. According to the World Economic Forum (2018), the Philippines ranked $55^{\text {th }}$ out of 137 participating countries in terms of higher education and ranked $76^{\text {th }}$ out of 137 countries in the quality of math and science education.

The state of science education today is influenced by several problems specifically the issue of inadequate instructional materials and teaching tools aligned to the learning outcomes prescribed by the department of education (DepEd). Teachers find it difficult to teach some science concepts and principles due to the scarcity of relevant, responsive, and researchbased learning materials. According to Jalmasco (2014), the lack of science education facilities is reflected in the poor quality of basic science and math education seen by the low achievement scores of Filipino students in various tests. In addition, instructional materials that are aligned to the target competencies are lacking.

In 2016, the Philippine DepEd started the implementation of the senior high school (SHS) across the country. The SHS aims to equip high school students for work, entrepreneurship, higher education, or middle - level skills development. This is a step up from the 10-year cycle, where high school graduates still need further education to be ready for the world (DepEd, 2016). It covers the past 2 years of the K-12 program and includes Grades 11 and 12, where students go through a core curriculum and subjects under a track of their choice.

In the curriculum, physical science is one of the core subjects offered across all tracks in Grade 11 and Grade 12, which requires $80 \mathrm{~h} / \mathrm{semester}$. The course deals with the evolution of one's understanding of matter, motion, electricity, magnetism, light, and the universe from ancient times to the present. It includes the application of physics and chemistry concepts in contexts such as atmospheric phenomena, cosmology, astronomy, vision, medical instrumentation, space technology, drugs, sources of energy, pollution and recycling, fitness and health, and cosmetics (K to 12 Senior High School Curriculum - Physical Science, 2016). Teachers teaching the physical science course have been faced with the inadequacy of K-12 ready materials. The development of learning materials that foster inquiry is an emphasis of curricular reform in K-12 science because inquiry has become a core element of science education over the past few decades (Meyer et al., 2013; Trumbull et al., 2005).

Several studies on the development of instructional materials in science have been made in the Philippines. These studies focused on the development and evaluation of microlab 
kits (Evangelista et al., 2014; Ocampo et al., 2015; Pastor et al., 2015), development of modules in physics (Auditor and Naval, 2014; Gagarin, 2003), development of science laboratory manual (Bayle, 2004), validation of workbook in science (Rubo, 2005), and module development for science investigatory project (Libranda, 2004). However, there are very few studies conducted on the development and validation of the workbook for SHS science.

With the issues on the scarcity of learning materials, teachers are challenged to develop appropriate instructional materials that may enhance student learning and may resolve the dilemma on the scarcity of reference materials. In response to the K-12 SHS curriculum, the development of the physical science workbook aims to facilitate more effective instruction in concretizing abstract concepts in physical science and to maximize the learning experience through the developed workbook, despite the limited resources in the public secondary school setting. This innovation is hoped to respond to the pressing need of basic education.

\section{Conceptual Framework}

Hofstein and Naaman (2007) argued that science cannot be meaningful to students without worthwhile practical experiences in the school laboratory. The K-12 basic education curricula must harness the $21^{\text {st }}$-century skills of the students. These skills include learning and innovation skills, information, media and technology skills, and life and career skills (Partnership for $21^{\text {st }}$ Century Skills, 2009). The main purpose of this study was to develop and evaluate an activitybased, learner-centered, and competency-based workbook on physical science that could be used in the lecture classes in the SHS.

Figure 1 shows the input-process-output model where a needs assessment and review of existing books were made, as part of the input (I). The process (P) included the design and development of the workbook, pilot of the workbook with college freshmen, revision of the workbook, and the final evaluation. The output $(\mathrm{O})$ of this study was a validated and evaluated Physical Science Workbook.

\section{Purpose of the Study}

The study aimed to develop and validate a workbook in physical science for SHS students. Specifically, this study aimed to (1) develop a physical science workbook, which was congruent with the K-12 competencies and outcomes-based

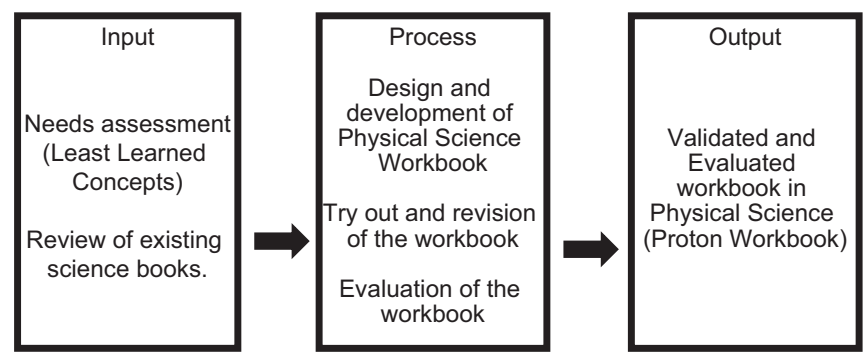

Figure 1: Paradigm of the study education; (2) establish the content and face validity of the workbook; (3) pilot test the workbook to an identified class; (4) validate the workbook; (5) revise/improve the workbook; and (6) evaluate the developed workbook.

\section{METHODOLOGY}

\section{Research Model}

This descriptive-developmental educational research focused on the development of instructional material in the form of an alternative workbook to facilitate learning of the least-learned and least-practiced concepts and skills of students in the SHS.

\section{Research Participants}

The study involved three groups of participants. The first group of participants was 50 randomly sampled undergraduate teacher education students from a government-run university in Central Luzon, the Philippines. The participants satisfied the following selection criteria: (1) A bona fide student of the university during the Academic Year (AY) 2014-2015; (2) enrolled under the program Bachelor of Secondary Education (BSEd) or Bachelor of Elementary Education; and (3) taking the physical science course at the time of the study. An informed consent form was secured before the involvement of the participants. These students were given a diagnostic test to determine the least learned competencies in physical science.

The second group of participants was the four expert-validators. These validators included one expert on instructional material development and three content experts. They evaluated the workbook's face and content validity based on the adequacy, coherence, appropriateness, and usefulness.

The third group of participants was the 24 students who evaluated the effectiveness of the activities in the workbook using the student's evaluation checklist. These students were enrolled in natural science one (physical science) course during the AY 2015-2016.

\section{Research Instruments \\ Diagnostic test}

The 30-item diagnostic test measured the least learned competencies of the students in physical science. The test was subjected to content and construct validity. The inter-item reliability was found to be high based on the item analysis conducted.

\section{Expert validator's instrument}

The expert validator's instrument was a standardized evaluation tool for the instructional materials adopted from the College of Education, Arts and Sciences of the University.

\section{Student evaluation checklist}

The student evaluation checklist was a researcher-made instrument subjected to content and construct validity. Likewise, the checklist was subjected to a reliability test and obtained a Cronbach's alpha value of 0.87 suggesting that the items have relatively high internal consistency. 


\section{Data Collection}

The product development of the workbook followed the ADDIE model (Figure 2). The Analysis, Design, Development, Implementation, and Evaluation (ADDIE) is an acronym for ADDIE. This model guides you through the process of creating effective educational courses and materials for your audience (Instructional Design, 2015). It is an instructional design model that has withstood the test of time and use. It is simply a "device" to help us think through a course's design. Although the model appears linear, it does not have to be followed rigidly or in a linear approach, especially if you already have course materials developed.

The following phases were followed in the study based on the ADDIE model:

Phase 1. Analysis: A diagnostic test among 50 undergraduate teacher education students was conducted in AY 2014-2015. This was to determine the least learned competencies in physical science, which became the basis of the activities included in the workbook. Likewise, the researchers reviewed selected physical science books published in the Philippines as part of the needs assessment.

Phase 2. Design: The researchers agreed for the selection of learning objectives, assessment instruments, and content of

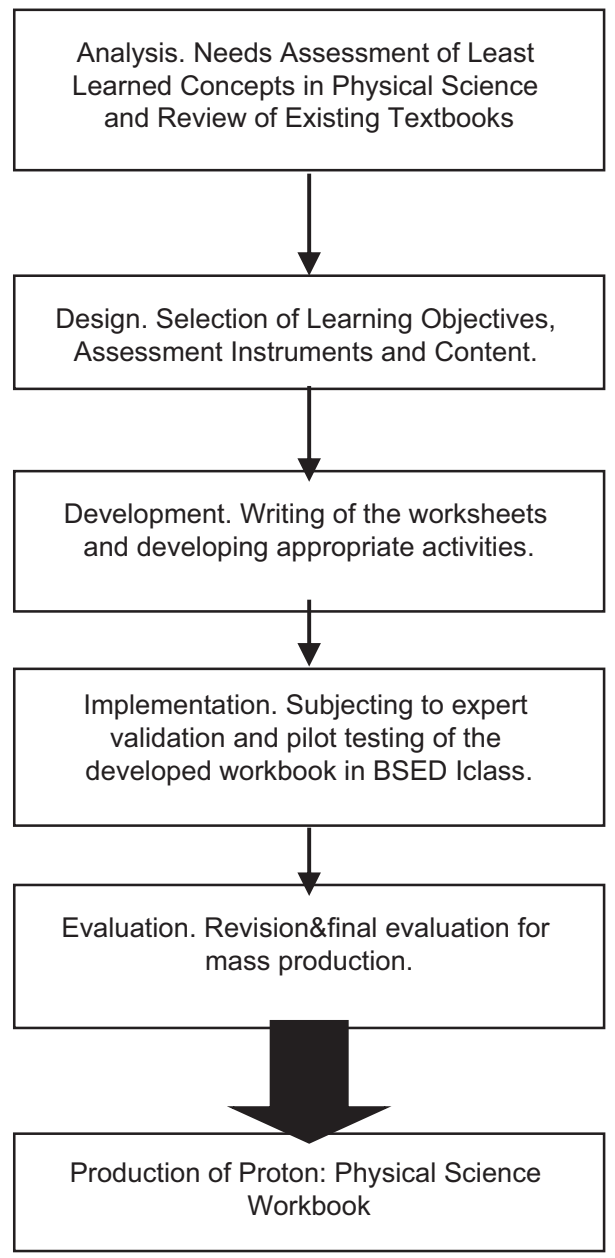

Figure 2: Product development chart of the workbook using the Analysis, Design, Development, Implementation, and Evaluation model each of the worksheets. Each worksheet contains the following parts: Introductory statement, learning outcomes, learning tasks, add-on vocabulary, and suggested readings.

Phase 3. Development: The researchers started writing the worksheets to be included in the workbook. Activities that were included are student-centered and reflective in nature.

Phase 4. Implementation: Before the actual use of the workbook, the researchers subjected it to an expert validation to gauge the workbook's face and content validity based on the adequacy, coherence, appropriateness, and usefulness. Four experts were requested to complete the expert validator's form. The group comprised of an Associate Professor specialized in instructional material development, an Associate Professor who is an expert in Chemistry, an Assistant Professor specialized in Physics, and an Associate Professor who mastered in Biology. The developed workbook was pilot tested with 24 BSEd students who were not part of Year 1 of the study. The workbook was pilot tested in the first semester of the AY 2015-2016 from June 2015 to October 2015. After each activity, student-participants were asked to evaluate the acceptability of each worksheet using the student evaluation checklist.

Phase 5. Evaluation: Experts' and students' verbal suggestions and comments were taken into consideration for the revision of the material. The revised workbook was then subjected to final evaluation.

\section{RESULTS AND DISCUSSION}

This study is all about the development and validation of a physical science workbook intended for SHS students. The workbook is supplemental material to the learning materials prescribed by the DepEd.

\section{The Developed Workbook}

Results of the students' diagnostic test in physical science served as the basis for the selection of concepts to be included in the workbook. Also considered in the topic selection were the expected competencies included in the SHS curriculum guide. Table 1 shows the final list of activities in the workbook.

The activities were included based on the least learned concepts, as indicated in the diagnostic test and need assessment. The completed workbook was first subjected to expert validation. Design, development, or even selection of instructional materials can be quite challenging depending on the subject, goals, target audience, context, and so on (Şendurur et al., 2016).

The developed workbook is titled "Proton: Workbook in Physical Science." It contains enrichment exercises which can expand the knowledge and understanding of the SHS students on the basic concepts of chemistry and physics. The topics included in this workbook were aligned with the competencies required in the K-12 curriculum. The worksheet contained several parts, which included the introductory statement, learning outcomes, activity proper, add-on vocabulary, and suggested readings (Table 2 ). 


\begin{tabular}{ll}
\hline \multicolumn{2}{l}{ Table 1: List of worksheets in the workbook } \\
\hline Worksheet number & Worksheet title \\
\hline 1 & Nature of science \\
2 & Tools used in the science laboratory \\
3 & Basic physical quantities \\
4 & Significant figures and scientific notation \\
5 & Conversion of measurements \\
6 & Classification of matter \\
7 & Historical development of atomic structure \\
8 & The subatomic particles \\
9 & Atomic orbitals \\
10 & Electronic configuration \\
11 & The periodic table of elements \\
12 & Writing and naming chemical formula \\
13 & Molecular weight and percentage composition \\
14 & Types of chemical reactions \\
15 & Balancing chemical equations \\
16 & Distance and displacement \\
17 & Speed and velocity \\
18 & Acceleration \\
\hline
\end{tabular}

\begin{tabular}{ll}
\hline Table 2: Parts of the worksheet \\
\hline Part & Description \\
\hline Introductory statement & $\begin{array}{l}\text { The part of the worksheet, which provides a } \\
\text { glimpse of the content of the worksheet. This } \\
\text { will give a prompt to the learners about the } \\
\text { tasks to be accomplished } \\
\text { It serves as the targets to be achieved at the } \\
\text { end of the worksheet. The learning outcomes } \\
\text { crafted are aligned with the competencies, } \\
\text { which need to be developed among the } \\
\text { learners } \\
\text { This part of the worksheet provides varied } \\
\text { learning activities, which can enhance } \\
\text { students' critical thinking, creative thinking, } \\
\text { problem-solving skills, and other basic science } \\
\text { process skills } \\
\text { The part of the worksheet wherein the learners } \\
\text { can learn additional science vocabulary related } \\
\text { to the activity performed } \\
\text { This part provides the list of bibliographical } \\
\text { entries that can be read by students to further } \\
\text { their conceptual knowledge and understanding } \\
\text { of the topic }\end{array}$ \\
Add-on vocabulary &
\end{tabular}

The developed workbook contains worksheets, which follow the same components, which are congruent with each other. Each worksheet has an introductory paragraph to give the students the idea of what topic they are working on. The learning outcomes spell out the targets that should be attained after performing the different activities specified in the learning tasks. The add-on vocabulary part of the worksheet expands students' word bank in science while the suggested readings may extend the learning of students about the topic they are working on.

The material is just one instructional material that teachers and students could use in enriching students' inquiry, conceptual knowledge, and understanding in physical science. The use of other learning materials to supplement the workbook is recommended to make the learners better understand the basic concepts of physical science. Today in most K-12 classrooms, textbooks serve as the principal tool and tutor of teaching and learning and have an enormous influence on what is taught in science classrooms and how the curriculum is presented (McDonald, 2016; Pingel, 2010; Roseman et al., 2001). It was assumed that well-designed inquiry-based tasks in science textbooks play an important role in supporting students' experience with scientific inquiry and developing understandings about scientific ideas (Yang \& Liu, 2016).

\section{Content and Face Validity of the Workbook}

Expert-validators were asked to validate the developed workbook. The criteria for evaluation include adequacy, coherence, appropriateness, and usefulness (Table 3).

As shown from the table, the validators strongly agreed that the developed workbook showed adequacy $(\mathrm{M}=3.85$; Standard deviation $[\mathrm{SD}]=0.05)$. Each of the indicators received a strongly agree remarks except with the indicator on pictorial images. It was suggested that more graphical and pictorial images be included in the workbook. Research literature suggests that the quality of learning material is enhanced if the material is designed to take into account learners' individual learning styles (Rasmussen, 1998; Riding \& Grimley, 1999).

In terms of coherence, the developed workbook got a very favorable rating $(\mathrm{M}=3.90 ; \mathrm{SD}=0.06)$ which meant that the validators strongly agreed in all the indicators. Although the indicator on the provision of practical work had the lowest mean, still the developed workbook was coherent with the skills to be developed. This finding supports the study of Windschitl (2009) who clarified that coherence with existing knowledge does not mean tailoring instruction to what teachers already know but rather taking into account their deeply engrained theories about "good" teaching and learning.

Furthermore, the validators strongly agreed on the appropriateness $(\mathrm{M}=3.90 ; \mathrm{SD}=0.10)$ and usefulness $(\mathrm{M}=3.95 ; \mathrm{SD}=0.05)$ of the workbook. All indicators received strongly agree on remarks. It was suggested, however, that the developed workbook should provide more differentiated activities, provide immediate needs, and encourage creative and critical thinking among the students. Content knowledge is very important and is related to student learning (Magnusson et al., 1992). Teachers with strong content knowledge are more likely to teach in ways that help students construct knowledge, pose appropriate questions, suggest alternative explanations, and propose additional inquiries (Alonzo, 2002; Gess-Newsome \& Lederman, 1995; Roehrig \& Luft, 2004).

Table 4 shows the summary of an expert's validation of the developed physical science workbook.

As reflected in Table 4, the developed workbook received a very favorable rating from the experts $(\mathrm{M}=3.90 ; \mathrm{SD}=0.06)$ which implied that the validators strongly agreed with all the 


\section{Table 3: Expert's validation of the physical science workbook}

\begin{tabular}{|c|c|c|}
\hline Criteria & Mean \pm SD & Remark \\
\hline \multicolumn{3}{|l|}{ Adequacy } \\
\hline 1. Instruction corresponds with activities & $4.00 \pm 0.00$ & SA \\
\hline 2. Learning activities satisfy the stated objectives & $4.00 \pm 0.00$ & SA \\
\hline 3. Provides independent activities & $4.00 \pm 0.00$ & SA \\
\hline 4. Evident graphical and pictorial images & $3.25 \pm 0.25$ & A \\
\hline 5. Concepts presented logically & $4.00 \pm 0.00$ & SA \\
\hline Weighted mean & $3.85 \pm 0.05$ & SA \\
\hline \multicolumn{3}{|l|}{ Coherence } \\
\hline 1. Contains relevant activities & $4.00 \pm 0.00$ & SA \\
\hline 2. Activities provide practical work & $3.50 \pm 0.29$ & SA \\
\hline 3. Activities develop creativity and resourcefulness & $4.00 \pm 0.00$ & SA \\
\hline 4. Provides relevant information for better understanding & $4.00 \pm 0.00$ & SA \\
\hline 5. Activities conform with the concepts & $4.00 \pm 0.00$ & SA \\
\hline Weighted mean & $3.90 \pm 0.06$ & SA \\
\hline \multicolumn{3}{|l|}{ Appropriateness } \\
\hline 1. Adapted to intended learners & $4.00 \pm 0.00$ & SA \\
\hline 2. Based on the NCTBS/SHS learning competencies & $4.00 \pm 0.00$ & SA \\
\hline 3. Provides immediate needs & $3.75 \pm 0.25$ & SA \\
\hline 4. Arranged in the correct sequence & $4.00 \pm 0.00$ & SA \\
\hline 5. Provides varied activities to sustain interest & $3.75 \pm 0.25$ & SA \\
\hline Weighted mean & $3.90 \pm 0.10$ & SA \\
\hline \multicolumn{3}{|l|}{ Usefulness } \\
\hline 1. Easy to understand & $4.00 \pm 0.00$ & SA \\
\hline 2. Provides knowledge and skill & $4.00 \pm 0.00$ & SA \\
\hline 3. Encourages creative and critical thinking & $3.75 \pm 0.25$ & SA \\
\hline 4. Serves as an instructional tool & $4.00 \pm 0.00$ & SA \\
\hline 5. Helps facilitate lesson presentation & $4.00 \pm 0.00$ & SA \\
\hline Weighted mean & $3.95 \pm 0.05$ & SA \\
\hline
\end{tabular}

Legend: Strongly agree (3.50-4.00); Agree (2.50-3.49); Disagree (1.50-2.49); Strongly disagree (1.00-1.49). SD: Standard deviation

aspects of the workbook. Usefulness $(\mathrm{M}=3.95)$ ranked first, followed by coherence $(\mathrm{M}=3.90)$, appropriateness $(\mathrm{M}=3.90)$, and adequacy $(\mathrm{M}=3.85)$. The expert validators provided positive feedback in the developed instructional material and were hopeful for the benefits it would provide to students' learning. This finding agrees with the research findings of several studies (Evangelista et al., 2014; Ocampo, 2015; Pastor et al., 2015). Tomlinson (1998) commented that the impact of instructional materials was achieved when materials have a noticeable effect on learners that are when the learners' curiosity, interest, and attention are attracted.

\section{Pilot Testing of the Workbook}

The developed workbook was subjected to initial pilot testing for further enhancements. Undergraduate teacher education students taking up physical science course during the AY 2015-2016 performed the activities in the workbook. Worksheets were given after each learning session to enhance the students' conceptual understanding. Students were asked to assess the acceptability of the 18 worksheet activities based on the given four-point Likert type evaluation sheet (Table 5).

The student's evaluation checklist was used to gauge the acceptability of the developed workbook among the
Table 4: Summary of expert's validation of the physical science workbook

\begin{tabular}{lclc}
\hline Criteria & Mean \pm SD & Remark & Rank \\
\hline Adequacy & $3.85 \pm 0.05$ & SA & 4 \\
Coherence & $3.90 \pm 0.06$ & SA & 2.5 \\
Appropriateness & $3.90 \pm 0.10$ & SA & 2.5 \\
Usefulness & $3.95 \pm 0.05$ & SA & 1 \\
Overall & $3.90 \pm 0.06$ & SA & \\
\hline Legend: Strongly agree & $(3.50-4.00)$, agree (2.50-3.49), disagree \\
$(1.50-2.49)$, strongly disagree (1.00-1.49). SD: Standard deviation
\end{tabular}

24 student-participants. Table 6 shows the summary of the students' evaluation based on the workbook's clarity of instructions, the attainability of learning outcomes, evidence of varied learning tasks, visual and esthetics, vocabulary enhancement, retention of concepts, interactivity, and student interest enhancement.

Table 6 shows that student-evaluators rated the developed workbook to be very much acceptable as revealed by the overall mean of $3.79(\mathrm{SD}=0.39)$. Flores $(2008)$ found that students with varied learning styles clearly preferred activities that matched their learning styles. That is why the developed 


\section{Table 5: Student's evaluation checklist

\begin{tabular}{|c|c|c|c|c|}
\hline Item & SA & A & D & SD \\
\hline 1. The instructions are easy to understand & & & & \\
\hline 2. Learning objectives are attainable & & & & \\
\hline 3. Varied activities are evident & & & & \\
\hline 4. Graphic organizers enhanced my interest & & & & \\
\hline 5. Word puzzles expanded my vocabulary & & & & \\
\hline $\begin{array}{l}\text { 6. The activities enhanced my understanding } \\
\text { of the lesson }\end{array}$ & & & & \\
\hline 7. I enjoyed answering the activities & & & & \\
\hline $\begin{array}{l}\text { 8. The activities increased my interest in } \\
\text { physical science }\end{array}$ & & & & \\
\hline
\end{tabular} \\ Legend: Strongly agree (SA); agree (A); disagree (D); strongly disagree (SD)}

\begin{tabular}{lcl}
\hline $\begin{array}{l}\text { Table 6: Students' evaluation of the activities in the } \\
\text { physical science workbook }\end{array}$ \\
\hline Worksheet & Weighted mean \pm SD & Remark \\
\hline 1 & $3.96 \pm 0.20$ & Very much acceptable \\
2 & $3.98 \pm 0.14$ & Very much acceptable \\
3 & $3.89 \pm 0.32$ & Very much acceptable \\
4 & $3.87 \pm 0.38$ & Very much acceptable \\
5 & $3.82 \pm 0.47$ & Very much acceptable \\
6 & $3.97 \pm 0.16$ & Very much acceptable \\
7 & $3.94 \pm 0.24$ & Very much acceptable \\
8 & $3.99 \pm 0.07$ & Very much acceptable \\
9 & $3.77 \pm 0.47$ & Very much acceptable \\
10 & $3.81 \pm 0.44$ & Very much acceptable \\
11 & $3.79 \pm 0.50$ & Very much acceptable \\
12 & $3.70 \pm 0.61$ & Very much acceptable \\
13 & $3.74 \pm 0.60$ & Very much acceptable \\
14 & $3.83 \pm 0.48$ & Very much acceptable \\
15 & $3.20 \pm 0.70$ & Much acceptable \\
16 & $3.92 \pm 0.28$ & Very much acceptable \\
17 & $3.58 \pm 0.49$ & Very much acceptable \\
18 & $3.25 \pm 0.43$ & Much acceptable \\
Overall & $3.79 \pm 0.39$ & Very much acceptable \\
\hline
\end{tabular}

Very much acceptable (3.49-4.00); much acceptable (2.50-3.00); not much acceptable (1.50-2.49); not at all acceptable (1.00-1.49). SD: Standard deviation

instructional material considered infusing various kinds of activities to address the multiple intelligences of the students.

The results of the study are congruent to the study of Auditor and Naval (2014) which showed that the developed modules were found acceptable for the tenth-grade physics students. Furthermore, Flores (2008) stated that it is not necessary to modify teaching styles, but there is a need to design activities to increase educational outcomes and student satisfaction. Likewise, the use of instructional materials in teaching improves the performance of the students and enables teachers to clarify their lessons (Leonen, 2016).

The evaluation results of both the experts and students were congruent with the previous study on material development. Based on Nunan's (1989) suggestions, good materials should: (1) Be clearly linked to the curriculum they serve; (2) be authentic in terms of text and task; (3) stimulate interaction; (4) allow learners to focus on formal aspect of the language; (5) encourage learners to develop skills in learning how to learn; and (6) encourage learners to apply their developing language skills to the world beyond the classroom.

\section{CONCLUSIONS AND RECOMMENDATIONS}

The study sought to develop and validate a workbook in physical science intended for the SHS students under the K-12 curriculum. The developed workbook was found to be very much acceptable as validated by the experts. The expert-validators strongly agreed that the instructional material possesses adequacy, coherence, appropriateness, and usefulness. The "Proton: Physical Science Workbook" had been evaluated as very much acceptable by the students. The workbook follows differentiated instruction and encourages independent learning. The learning material was aligned to the competencies required in the SHS.

A pre-test-post-test quasi-experimental research design must be conducted to assess the effectiveness of the worksheets in improving student conceptual understanding in physical science. The developed instructional material may also be used by other SHS teachers in their respective classes to assess potential problems in its utilization and to further validate its effectiveness. Further scrutiny and review may also be done by experts to review the concepts and principles integrated into the workbook. The developed workbook can serve as a prototype in developing workbooks for other core courses in SHS.

Since the study only involved a smaller population for the pilot-testing, further study may be done in a larger student population to further assess the workbook's acceptability. A follow-up study may also be conducted in the future to ascertain the congruence of the activities in the workbook to the competencies required in a physical science course. The use of qualitative approach is also suggested to further determine the workbook's acceptability.

\section{ACKNOWLEDGMENTS}

The researchers would like to thank the following people for making this research possible: Dr. Luz N. Corpuz, BSEd Program Chair, for the support and encouragement; Prof. Joseline R. Tamoria, for the constructive criticisms in the workbook development; expert validators for the suggestions; and BSEd students (AY 2014-2015 and AY 2015-2016), for the active participation.

\section{REFERENCES}

Alonzo, A.C. (2002). Evaluation of a Model for Supporting the Development of Elementary School Teachers 'Science Content Knowledge. Charlotte, NC: Proceedings of the Annual International Conference of the Association for the Education of Teachers in Science.

Auditor, E., \& Naval, D. J. (2014). Development and validation of tenth grade physics modules based on selected least mastered competencies. International Journal of Education and Research, 2(12), 145-152.

Bayle, N. (2004). Development and Validation of Laboratory Manual in 
Physics (Doctoral Dissertation Eulogio “Amang” Rodriguez Institute of Science and Technology, Manila).

Department of Education (DepEd). (2016). Senior High School. Available from: http://www.deped.gov.ph/k-to-12/faq/senior-high-school. [Last retrieved on 2016 Jun 04].

Evangelista, E., Ayuste, T.O.D., Belmi, R.M., Butron, B.R., Cortez, L.A.S., Evangelista, L.T., Tondo, J.E. (2014). Development and evaluation of grade 7 and grade 8 biokit. The Normal Lights, 8(2), 152-171.

Flores, C.D. (2008). Teaching Styles of Social Studies Teachers of Tarlac National High School and their Students' Learning Styles (Master's thesis, Tarlac State University, Tarlac).

Gagarin, C. (2003). Module in Physics I: Development and Evaluation (Master's thesis, Eulogio “Amang” Rodriguez Institute of Science and Technology, Manila).

Gess-Newsome, J., \& Lederman, N.G. (1995). Biology teachers' perceptions of subject matter structure and its relationship to classroom practice. Journal of Research in Science Teaching, 32(3), 301-325.

Hofstein, A., \& Naaman, R.M. (2007). The laboratory in science education: The state of the art. Chemistry education research and practice, $8(2)$, 105-107.

Instructional Design. (2015). The ADDIE Model. Available from: http:// www.instructionaldesign.org/models/addie.html. [Last retrieved on 2016 Jun 05].

Jalmasco, N.M. (2014). Science Education Realities. The Manila Times. Available from: http://www.manilatimes.net/science-educationrealities/100096. [Last retrieved on 2016 Jun 01].

$\mathrm{K}$ to 12 Senior High School Curriculum Physical Science. (2016). K to 12 Basic Education Curriculum Senior High School Core Subject. Available from: https://www.drive.google.com/file/d/0BwSTMpKEx 4a0RHOGZ6dEZqbUU/view. [Last retrieved on 2019 Oct 18].

Leonen, R.B. (2016). Development and Validation of Worktext in Chemistry10. Unpublished Research: Don Mariano Marcos Memorial State University.

Libranda, E.D. (2004). Development and Validation of a Module on the Conduct of Science Investigatory Project: A Cooperative Learning Approach (Master's thesis). Philippine Normal University, Manila.

Magnusson, S., Borko, H., Krajcik, J., \& Layman, J. (1992). The Relationship between Teacher Content and Pedagogical Content Knowledge and Student Content Knowledge of Heat Energy and Temperature. Boston, MA: National Association for Research in Science Teaching. (Eric Document Reproduction Service No. ED385435).

McDonald, C.V. (2016). Evaluating junior secondary science textbook usage in Australian schools. Research in Science Education, 46(4), 481-509.

Meyer, D.Z., Meyer, A.A., Nabb, K.A., Connell, M.G., \& Avery, L.M. (2013). A theoretical and empirical exploration of intrinsic problems in designing inquiry activities. Research in Science Education, 43(1), 57-76.

Nunan, D. (1989). Designing Tasks for the Communicative Classroom. Cambridge: Cambridge University Press.
Ocampo, C.A., de Mesa, D.M.B., Ole, A.F., Auditor, E., Morales, M.P.E., Sia, S.R.D., \& Palomar, B.C. (2015). Development and evaluation of PHYSICS MICROLAB (P6-Mlab) Kit. The Normal Lights, 9(1), 134-158.

Partnership for Twenty First Century Skills. (2009). P21 Framework Definitions. Available from: http://www.p21.org/storage/documents/ P21_Framework_Definitions.pdf. [Last retrieved on 2019 Oct 18].

Pastor, C.J.M., Marasigan, A.C., Aranes, F.Q., Camacho, V.M.I., Datukan, J.I., Roque, A.P., Ocampo, C.A. (2015). Initial validation of the chemistry microlab kit (Chem. $\mu \mathrm{Lab}$ Kit) in facilitating learning of selected chemistry concepts for k-12 science. The Normal Lights, 9(2), 180-204.

Pingel, F. (2010). Guidebook on Textbook Research and Textbook Revision. $2^{\text {nd }}$ ed. Pairs: United Nations Educational, Scientific and Cultural Organization.

Rasmussen, K.L. (1998). Hypermedia and learning styles: Can performance be influenced? Journal of Multimedia and Hypermedia, 7(4), 291-308.

Riding, R., \& Grimley, M. (1999). Cognitive style and learning from multimedia materials in 11-year children. British Journal of Educational Technology, 30(1), 43-59.

Roehrig, G.H., \& Luft, J.A. (2004). Constraints experienced by beginning secondary science teachers in implementing scientific inquiry lessons. International Journal of Science Education, 26(1), 3-24.

Roseman, J.E., Kulm, G., \& Shuttleworth, S. (2001). Putting Textbooks to the Test. Available from: http://www.project2061.org/publications/ articles/articles/enc.htm. [Last retrieved on 2019 Oct 18].

Rubo, E. (2005). Validation of Workbook in Science and Technology (Master's Thesis, Philippine Normal University, Manila).

Şendurur, E., Ersoy, E., \& Çetin, I. (2016). The design and development of creative instructional materials: The role of domain familiarity for creative solutions. International Journal of Technology and Design Education, 28(2), 507-522.

Tomlinson, B. (1998). Materials Development in Language Teaching. Cambridge: Cambridge University Press.

Trumbull, D.J., Bonney, R., \& Grudens-Schuck, N. (2005). Developing materials to promote inquiry: Lessons learned. Science Education, 89(6), 879-900.

Windschitl, M. (2009). Cultivating $21^{\text {st }}$ Century Skills in Science Learners. How Systems of Teacher Preparation and Professional Development will Have to Evolve. Available from: https://www.sites.nationalacademies. org/cs/groups/dbassesite/documents/webpage/dbasse_072614.pdf. [Last retrieved on 2016 Jun 14].

World Economic Forum (WEF). (2018). Global Competitiveness Report (2017-2018). Available from: http://www3. we forum.org/docs / GCR 2017-2018/0 5 Ful1Report/ TheGlobalCompetitivenessReport2017\%E2\%80\%932018.pdf. [Last retrieved on 2019 Oct 18].

Yang, W., \& Liu, E. (2016). Development and validation of an instrument for evaluating inquiry-based tasks in science textbooks. International Journal of Science Education, 38(18), 2688-2711. 